\title{
The harm argument against surrogacy revisited: two versions not to forget
}

\author{
Marcus Johansson Agnafors
}

\section{Linköping University Post Print}

\section{Tweet}

N.B.: When citing this work, cite the original article.

The original publication is available at www.springerlink.com:

Marcus Johansson Agnafors, The harm argument against surrogacy revisited: two versions not to forget, 2014, Medicine, Health care and Philosophy, (17), 3, 357-363.

http://dx.doi.org/10.1007/s11019-014-9557-x

Copyright: Springer Verlag (Germany)

http://www.springerlink.com/?MUD=MP

Postprint available at: Linköping University Electronic Press

http://urn.kb.se/resolve?urn=urn:nbn:se:liu:diva-109365 


\section{The Harm Argument against Surrogacy Revisited: Two Versions Not to Forget}

Surrogacy has always been surrounded by controversy. While the controversy has perhaps diminished slightly in recent years, many of the ethical issues associated with surrogacy remain unsolved. In this article I will discuss and develop the harm argument against surrogacy. According to the harm argument, surrogacy is morally problematic because it causes harm, or increases the risk of harm. In recent years it has come under attack due to what is often deemed to be accumulating empirical evidence showing that there are no substantial harms resulting from the practice. Against this development, I will argue that the harm argument cannot be dismissed that easily. I present two different and novel versions of the harm argument that deserve careful consideration, and I argue that they escape the criticism leveled against the standard version and hence warrant our continued attention. The first version takes as its starting point the emerging evidence showing that the gestational mother and the child are connected prenatally, and argues that to severe that bond constitutes harm to the child. The second version notes that there is an inherent conflict between the practice of surrogacy and high levels of what is commonly called maternal-fetal attachment (MFA). As low levels of MFA increases the risk of harm to both the gestational mother and the fetus, surrogacy qua practice inherently involves risks to the fetus that the average pregnancy does not. While the harm argument is not in itself conclusive regarding the moral status of surrogacy, or decisive in matters of social policy, my aim here is to show that it carries more weight than is often attributed 
to it, and that it warrants careful and continued attention by both ethicists, decision-makers and practitioners.

\section{Surrogacy and the Harm Argument}

Surrogacy is the reproductive practice in which a woman agrees to carry a baby full-term and, after birth, to surrender any parental claims to the child. Surrogacy comes in one of two forms: genetic surrogacy, in which sperm from a man in the commissioning couple is used to impregnate the surrogate, and gestational surrogacy, in which blastocysts are produced through in-vitro fertilization using both sperm and egg from the commissioning couple, and then implanted in the uterus of the surrogate. In gestational surrogacy, the surrogate has no genetic connection with the child she carries. Below, the discussion will be limited to gestational surrogacy, as it is often perceived as the least problematic version due to the lack of genetic connections between the surrogate and the child that might complicate the arrangement. Surrogacy is further divided into commercial and altruistic surrogacy. In the commercial version, the surrogate offers her services in exchange for money, or some other form of payment. In the altruistic version, the surrogate voluntarily agrees to carry the baby, but not for payment. While there are specific harms that befall one version but not the other, both are subject to the family of arguments claiming that surrogacy is harmful.

The commercial market in surrogacy arrangements has expanded rapidly. In India alone - arguably the largest provider of surrogates - commercial surrogacy is estimated to be a $\$ 3,2$ billion (per year) industry, with more than 25 , 
000 babies having been born in surrogacy arrangements; half of them being the offspring of Westerners (Shetty 2012). A part of the explanation for this is India's lax regulation of surrogacy (Gupta 2011; Rimm 2008-2009). Another, arguably large, part of the explanation is the comparatively low price. In India the total cost of a surrogacy pregnancy is approximately $\$ 22,000$ to $\$ 35,000 .{ }^{1}$ By comparison, in the United States, where the market also seems to be increasing, a commercial first-time surrogate can be paid $\$ 15,000$ to $\$ 30,000$ plus expenses alone, and the complete process comes with a price of $\$ 50,000$ to $\$ 250,000$ to be paid by the parents-to-be. ${ }^{2}$ Reliable statistics about surrogacy in a Western context are difficult to come by. Whatever statistics there are however, seem to indicate a dramatic increase in recent years. For instance, Gugucheva (2010) estimates the number of children born in 2008 to gestational surrogates in the United States to close to 1,400 - almost twice the number of children born to gestational surrogates in 2004.

The traditionally view on surrogacy has been one of skepticism, among both scholars and lay people; a skepticism fuelled by several controversial cases, such as the cases of Baby M and Baby Manji (Case Report In Re Baby M, 1988; Parks, 2010). Although empirical studies on attitudes toward surrogacy are surprisingly scarce and the available evidence local or anecdotal to its nature (Constantinidis and Cook, 2012), the existing studies seem to confirm the skeptical view. The majority of the various samples have negative or agnostic attitudes toward gestational surrogacy (Japan being the exception) (Baykal et al,. 2008; Kovacs et al., 2003; Lasker and Murray, 2001; Suzuki et al., 2011). If focusing on surveys on commercial surrogacy, an increase in negative attitudes is 
reasonable to expect (Krishnan, 1994). Among scholars, an equally strong resistance against surrogacy and in particular its commercial version is common. For instance, Rimm (2008-2009, p. 1443) notes the "[...] strong critiques of the practice of surrogacy advanced by courts, legislatures, and legal scholars."

That said, people's views on the moral legitimacy of surrogacy in general are changing (Brazier, Campbell and Golombok, 1998, p. 30). From a state of "moral panic" (Scott, 2009), a more permissive attitude appears to be furthered by several general trends and developments. Most noticeable, much of the worries that concerned the early writers in the debate over surrogacy concerns often framed in terms of harm - appear to have been left unfulfilled. As many of the predicted but undesired consequences of a fairly widespread practice of surrogacy have seemingly failed to materialize, the harm argument seems no longer fashionable.

As a rather sweeping and elusive argument, the harm argument covers a number of possible harms: Harm to the surrogate (physical, emotional, or financial), harm to the child, harm to the surrogate's own children, and harm to society in general. However, the most pressing concern tends to be the postpartum social and psychological wellbeing of the child and the surrogate. According to the harm argument then, surrogacy gives rise, or is likely to give rise, to individual harms that are substantial enough to establish that surrogacy is prima facie morally problematic, or even impermissible. $^{3}$

The harm argument is often employed only implicitly. It is commonly stated as a precautionary argument in relation to policy, claiming that since we cannot exclude the possibility of harm to children or the surrogate we 
should avoid the risk completely by banning or restricting surrogacy (for examples of such explicit worries, see Allen, 1987; Anderson, 1990; 1993; Appleton, 2001; Brinig, 1995; Schneider, 1990; Tong, 1990; Warnock, 1984). However, while the harm argument is relatively seldom pressed as an explicit argument against surrogacy, a large number of scholars have nevertheless targeted the harm argument as if it was the strongest argument available against surrogacy. Attacking the harm argument usually involves pointing to empirical data suggesting that there are no substantial harms that threaten the child or the surrogate. Doing so, the versions of the harm argument that are usually targeted appear to be successfully refuted. For instance, Humbyrd (2009, pp. 112-113) refers to a study showing that non-commercial surrogates in Britain did not "experienced any doubts or difficulties while handing over the baby, and the surrogacy experience was overwhelmingly positive for all women involved". Adding a commercial component seems to have little negative impact on the experience of handing over the child to the commissioning couple (van den Akker, 2007). In general, the surrogates seem to have experienced few psychological problems during and after the pregnancy (Jadva et al., 2003), and Andrews (1995, p. 2354) notes that "[...] the risks posed by surrogacy to women occur rarely and do not seem significantly different from the risks ordinarily assumed by women in other areas of their lives[.]" Moreover, Jackson (2001, p. 296) argues that worries about harm to the surrogate's other children are equally unjustified, and gains some support from Jadva and Imrie (2014). We should rely on the surrogate's best judgment, according to Jackson, since "[ [...] unless 
children are likely to suffer significant harm, the law normally assumes that parents are best able to make decisions about their children's upbringing."4

Concerning the welfare of children resulting from surrogacy, the empirical studies seem to point in the same (harmless) direction. With a number of children resulting from surrogacy approaching puberty, they seem to be doing as well as non-surrogacy children (Edelmann, 2004; Golombok et al., 2011). It also appears that couples seeking a surrogacy arrangement or an IVF treatment are more stable than the average couple, indicating that children who are the outcome of surrogacy arrangements may be enjoying better family conditions than other children (Andrews 1995, p. 2355).

Now, given the empirical data gathered, are we intellectually permitted not to reject the harm argument altogether? In what follows, I will argue that a rejection of the harm argument is unjustified. Although the versions of the harm argument I will defend below will not determine the moral status of surrogacy conclusively, they will reintroduce the harm argument as a vital consideration that must be taken into account in any ethical discussion over surrogacy. Although the argument presented below relies on empirical findings that have yet to provide us with a complete picture, the evidence is emerging, and the arguments thus rely on a discernible trend within empirical and psychological sciences. While this will constitute a red flag in the eyes of the proponents of surrogacy, it should be noted that such trends are usually all we have to rely upon in many contested areas of ethics. Furthermore, it should also be added that the studies referred to above, used to rebut the standard harm argument, suffer from the same youthful immaturity. The findings often said to falsify the harm 
argument are fairly recent, scarce and highly situational. They are also ridden with methodological problems, such as reliance on self-reporting, second-hand information, high dropout rates, and biased or non-representative selections (see Andrew and Douglass, 1991-1992; Ciccarelli and Beckman, 2005). Incomplete evidence is therefore not an acceptable reason for refusing to take the proposed version of the harm argument seriously.

The First Revised Argument from Harm - The Significance of Attachment

Below, I will argue that separating the newborn child from the surrogate always involves harm to the child. Although this harm is not necessarily harm all things considered, it is nevertheless a harm that must be considered when ethically assessing the practice of surrogacy; at present, this is rarely, if ever, done.

In common opinion, there is an undisputable and stable genetic connection holding between the (genetic) mother and the child. ${ }^{5}$ But genes do not provide the only persistent connection between a child and a woman. In fact, a gestational mother is not just a temporary "carrier" of the baby. The surrogate will also develop a connection to the fetus, and, most importantly, the fetus to the surrogate. This bond, which is not to be confused with MFA, ${ }^{6}$ is important to the future development of the fetus and subsequent child, and it therefore constitutes a substantial harm if violated. As all surrogacy arrangements per definition violate such connection, surrogacy inescapably harms the resulting child. 
The argument itself is fairly straightforward: First, note that fetuses are aware of and responsive to the environment outside the womb. They learn to recognize, in utero, music, language melodies, flavors, smells, and the voice of the gestational mother (Kisilevsky et al., 2009; Mampe et al., 2009; Mennella et al., 2001). The immediate implication of this is that the fetus develops a relationship, conscious or not, to the environment outside the womb and to its gestational mother. Infants are thus not blank slates, relation wise. The relation building naturally continues post partum. Infants are then prewired to very rapidly form attachment bonds to a caregiver (Moriceau and Sullivan, 2005). The prenatal priming and predisposition to develop full-blown attachments are what enable a very rapid development of an important filial attachment; an attachment bond to its mother constituting the secure foundation from which the infant learns to interact with the world (Hepper, 1996).

What is important here is that the attachment bond is starting to form prenatally. While interrupting this process does not mean that the infant will not develop an attachment, it is hindered in its process of doing so, and having one's chances of successfully developing a filial attachment reduced constitutes harm. Such harm is consistently ignored or downplayed in the literature on surrogacy, as the child is implicitly assumed to be tabula rasa; whatever happens to them in the process of surrogacy will have no long-term effects. For instance, Jackson (2001, p. 296) states that "[s]ince children born through surrogacy are generally handed over at birth, it might be supposed that surrogacy would have comparatively little impact upon children's long term wellbeing." Such claim is, of course, never substantiated. 
The significance of such harm is not to be ignored. Successfully developing an attachment is crucial to the child, as the nature and quality of early attachment to a caregiver has consequences for the child's future social and emotional functionings (Bowlby, 1969; Cassidy and Shaver, 2010; Hofer, 2006; Hrubý et al., 2011). ${ }^{7}$ Social and emotional dysfunctioning is clearly not an outcome that can easily be swept aside, and whatever intentional impact on a child's development that increases the risk of such dysfunctioning is a harm that must be carefully considered.

The child is then harmed to the extent that the separation from the surrogate (the gestational mother) increases its difficulty to successfully form a healthy attachment bond, since such attachment is crucial to successfully developing social and emotional functionings. As stressed earlier, this is not to say that a child whose attachment process is interrupted cannot, or will not, develop normal emotional and social functionings. Thankfully, the child's adaptive capacities and a loving environment are likely to ensure a healthy development. But pointing to apparently normal families and teenagers, or the potential or likely development into such, does not suffice to show that surrogacy involves no morally relevant harm, just as it cannot be proven that a man has not suffered a great harm when, say, losing a leg ten years ago, by showing that he feels fine today, or that divorces are not harmful because children and parents are usually fully functional individuals in the long run. ${ }^{8}$ Moreover, such compensated harms are likely to go unnoticed and to remain unexplored, which also accounts for the seemingly unchallenged view that there are no such harms involved in surrogacy. 
Note that the popular non-identity problem (Parfit, 1984) has no relevance here. To see why, ponder the following example of the non-identity problem: A woman decides to improve the odds of getting pregnant by taken an effective drug that, unfortunately, also has moderately harmful effects on the resulting child's development. In its teens, the child accuses its mother of having harmed him, by taking the dangerous drug and thereby causing him to suffer from, say, a certain physical handicap. Now, most people would find such complaint perfectly legitimate. However, as even the slightest change in the course of events will cause a different sperm to fertilize the egg - such as spending 15 minutes going to the drug store to buy the drug - the handicapped child actually owes his entire existence to the very fact that his mother took the harmful drug (all other things being equal). Since he has not suffered harm compared to some other self of his (he is non-identical with the person that would have been born had his mother not taken the drug), there is no basis for saying that he has suffered harm and that his mother has harm him, or even harmed anyone by her action.

But the non-identity problem has no bearing on version of the harm argument proposed here. When appealing to the existence of maternal-fetal connections, we are no longer discussing harms to children in general, or to future individuals, but to a specific and already existing individual. While the fetus is still developing, the conception is done with and the basic genetic setup in place. Moreover, the harmful act is that of severing of the bond between the child and its gestational mother, and that action takes place post-partum, at a point in the child's development where most people would attribute full moral relevance and 
status to it. Of course, it can be retorted that the version of the harm argument presented here does not suffice to establish a ban on surrogacy agreements, or to establish its immoral nature, since the surrogacy agreement predates the conception of the child. Thus, if the life of the child is worth living, she cannot rationally complain about the surrogacy agreement since she would be nonexistent was it not for that very arrangement. A fortiori, surrogacy is in that child's interest. But such an objection misses its target. True, if the non-identity problem is a general quandary we cannot navigate our way out of, surrogacy agreements by themselves cannot be said to cause harm to the child. But severing the mother-child relation can, as it constitute an actual harm to an actual individual subsequent to conception. So the version of the harm argument here proposed implies that while being a gestational mother does not harm the child, relinquishing the child to the commissioning couple does. Hence, surrogacy arrangements involving the gestational mother handing over the child - which clearly is an intrinsic element to the practice surrogacy - also involve harm to the child.

Last, note also that, despite what will likely be the immediate objection from many of the critics, the harm argument as described above does not have any substantial implications regarding the moral status of abortion. As the argument has been formulated, the relevant harms are harms to the resulting child. Although the fetus can arguably suffer harm by the same reasoning as the one employed in the argument, such harm is premised on its continued existence. The above version of the harm argument is therefore irrelevant to the question of abortion. 
The Second Revised Argument from Harm - Surrogacy and MFA

The first revised version of the argument from harm relied on a connection between the fetus and the surrogate incurred through the gestational process. That connection should not be confused with maternal-fetal attachment (MFA; see DiPietro, 2010 for a short introduction). MFA is, in contrast to the relation described earlier, an emotional care giving relation extending from mother to fetus/child (Walsh, 2010); a relation which develops during pregnancy as well as post partum.

The phenomenon of MFA complicates the moral landscape of surrogacy considerably, despite seldom recognized as a ethically relevant phenomenon. In so far it has been recognized as relevant, MFA has been framed as constituting a potential harm, if violated, to the mother (e.g., Andrews and Douglass, 1991-1992; van den Akker, 2007). But that is arguably a much too narrow of the consequences and importance of MFA. MFA is considered as beneficial for both the child and the mother, as it strengthens the mother's overall willingness to care for her child. But, crucially, a lack of MFA also puts the fetus and the subsequent infant at risk. In the ethical discussion over surrogacy, this is rarely acknowledged; instead, tactics involving keeping the surrogate's nonownership over the child in focus, thereby preparing her for a smooth process when handing over the baby to the commissioning couple, is largely taken as nonproblematic with only beneficial effects for all parties involved. But such assumption ignores the evidence showing that encouraging MFA is conducive to 
the mother's health (e.g, lowering the risk of post-partum depressions; Goecke et al., 2012) and that the absence of MFA will actually be indirectly detrimental to the child's health, as low attachment levels tend to increase the risk of the mother engaging in various forms of fetal abuse (e.g., smoking, drinking alcohol, etc.; Lindgren, 2001; Laxton-Kane and Slade, 2002).

Now, there is evidence that surrogates do not develop MFA to the same extent as pregnant women who intend to keep the child (Fischer and Gillman, 1991); a deficit due to the intrinsic motivation of women choosing to become surrogates, or due to external pressure and encouragement not to bond with the fetus. In so far a lack of MFA is inherent or encouraged in the practice of surrogacy, then surrogacy is harmful in the sense that it put a fetus at risk in a way a normal pregnancy generally do not. Note that even if dismissing Fischer and Gillman's data as a mere coincidence, a plausible case can be made that low levels of MFA is closely tied to surrogacy, and hence that we can expect lower levels of MFA in surrogacy cases. The argument can be outlined as follows:

(1) It is a very strong preference of the commissioning couple (or individual) and the surrogacy broker (if there is one) that the surrogacy arrangement is completed without problems.

(2) A surrogate refusing to hand over the baby is a paradigmatic case of a surrogacy arrangement that does not go smoothly.

(3) Hence, the commissioning couple (and the surrogacy broker) has a vested interest in minimizing factors that will prevent the surrogate from handing over the baby. 
(4) High levels of MFA will increase the likelihood of the surrogate refusing to hand over the baby.

(5) Hence, the commissioning couple has a very strong incentive to keep the surrogate from developing high levels of MFA.

That (1) - (5) is not a mere piece of hypothetical reasoning is evidenced by the frequent suggestion that surrogates should undergo psychological screening in order to find and select surrogates that will not have any problems handing over the child, or that surrogates should be actively discouraged from making a emotional connection to the fetus (e.g., van den Akker, 2007; Wertheimer, 1992; 1996). Further, the plausibility of (1) - (5) is even likely to be greater where there is a surrogacy broker involved, as financial incentives and motives of prestige enter into the equation. ${ }^{9}$

A proponent of surrogacy thus seems to be caught between Scylla and Charybdis: To the extent one succeeds in facilitating the actual exchange by avoiding the formation of MFA, one acts prima facie immorally as one thereby increases the risk of harm to the child, as well as to the gestational mother; and in so far one allows or encourages the formation of a sound attachment, which appears to have a protective effect on the child, one potentially subjects both the surrogate and the commissioning party to great distress when time comes to hand over the baby.

It might be objected that there are other interests at play as well. Most prominently, the reasoning made explicit in (1) - (5) is countered by a strong interest in the well-being of the child and thus a motivation to ensure high 
levels of MFA. However, such countering motivation does not imply that surrogacy is morally neutral in that respect. Surrogacy still holds an obvious and inherent potential for generating dilemmas, and such characteristic does not count in its favor. Hence, the kind of potential harm discussed here does not enter, or leave, the ethical assessment of surrogacy as a conclusive consideration, but it remains a consideration that needs to be taken seriously. The potential harms need to be factored into any decent analysis of the ethical status of surrogacy.

\section{Concluding Remarks}

As pointed out above, neither of the two versions of the harm argument presented here provides us with a conclusive reason on any of the moral issues involved in the practice of surrogacy. They do, however, provide us with reason to treat the practice of surrogacy with some suspicion. While surrogacy can certainly bring tremendous joy to couples that cannot conceive on their own, surrogacy should not be treated as harmless.

\section{Notes}

${ }^{1}$ For instance, see Medical Tourism Corporation (online) and Shetty (2012). The prices seem to have undergone a sharp increase. Compare with the prices cited in Lee $(2009,278)$ and Humbyrd $(2009,111)$.

${ }^{2}$ For instance, see Rimm (2008-2009, 1444), Shetty (2012) and Growing Generations (online). Again, the sharp increase in prices is an indication of the 
booming market for surrogacy. For examples of price levels just a few years ago, see Drabiak et al. (2007).

${ }^{3}$ Hence arguments referring to societal or systemic harms are excluded from the harm argument as characterized above. For examples of such arguments, see Anderson (1990); (1993); (2000); Satz (2010); Wertheimer (1992); (1996); Wilkinson (2003).

${ }^{4}$ That said, Jackson's argument is hardly reassuring, since, first, the law is an imperfect moral guide and, second, parents are normally "best" able to make decisions regarding their children's wellbeing in some areas in life, not generally - not, for instance, when it comes to education, medical needs, and so on. As Jackson herself points out, thorough research on this subject is lacking, and it is precisely this that entails that we do not yet know if this is one of the areas to which parental expertise extends.

${ }^{5}$ However, recent developments in epigenetics show that the fetus is highly receptive to genetic "reprogramming", meaning that the gestational mother can actually influence the genetic setup of the fetus she is carrying (Nafee et al., 2008). Hence, not even genetics offers a completely stable connection.

${ }^{6}$ MFA is a one-sided emotional connection - an aspiring caregiver relation - on behalf of the gestational mother. The connection described above has the nature of a dependence relation, according to which the fetus is dependent on the proximity to the gestational mother for aspects of its development.

${ }^{7}$ The theory describing such attachment is known as Attachment Theory (originally explored by Bowlby 1969); not to be confused with MFA. 
${ }^{8}$ For instance, consider an example offered by Shiffrin (1999, pp. 127-128), in which a golden bar is dropped from the sky and hits an (non-wealthy) individual out for a stroll, breaking his arm. While the gold makes him obscenely rich - and thus presumably better off overall - it seems that he has nonetheless suffered a harm; a harm that, I believe, warrants additional compensation.

${ }^{9}$ The fact that the adverse effects of low levels of MFA are culturally dependent e.g., drinking will be less of a problem in some highly religious cultures - does not invalidate the argument, as the problem of low levels of MFA is a motivational problem rather than one concerned with specific acts.

\section{References}

Allen, Anita. 1987. Privacy, surrogacy, and the Baby M case. Georgetown Law Journal 76 (5): 1759-92.

Anderson, Elizabeth. 1990. Is women's labor a commodity? Philosophy \& Public Affairs 19: 71-92.

Anderson, Elizabeth. 1993. Value in ethics and economics. Cambridge, Mass.: Harvard University Press.

Anderson, Elizabeth. 2000. Why commercial surrogate motherhood unethically commodifies women and children: Reply to McLachlan and Swales. Health Care Analysis 8: 19-26.

Andrews, Lori. 1995. Beyond doctrinal boundaries: A legal framework for surrogate motherhood. Virginia Law Review 81: 2343-2375. 
Andrews, Lori, and Lisa Douglass. 1991-1992. Alternative reproduction. Southern California Law Review 65 (1): 623-682.

Appleton, Tim. 2001. Surrogacy. Current Obstetrics \& Gynaecology 11 (4): 256257.

Baykal, Baris, Cem Korkmaz, Seyit Temel Ceyhan, Umit Goktolga, and Iskender Baser. 2008. Opinions of infertile Turkish women on gamete donation and gestational surrogacy. Fertility and Sterility 89: 817-822.

Bowlby, John. 1969. Attachment. New York: Basic Books.

Brazier, Margaret, Alasdair Campbell, and Susan Golombok. 1998. Surrogacy. Review for health ministers of current arrangements for payments and regulation: Report of the review team. Stationery Office, UK.

Brinig, Margaret Friedlander. 1995. A maternalistic approach to surrogacy: Comment on Richard Epstein's 'surrogacy: The case for full contract enforcement'. Virginia Law Review 81: 2377-2399.

Cassidy, Jude, and Phillip Shaver, eds. 2010. Handbook of attachment: Theory, research, and clinical applications, 2 ed. New York: Guilford Press.

Ciccarelli, Janice, and Linda Beckman. 2005. Navigating rough waters: An overview of psychological aspects of surrogacy. Journal of Social Issues 61 (1): 21-43.

Constantinidis, Deborah, and Roger Cook. 2012. Australian perspectives on surrogacy: The influence of cognitions, psychological and demographic characteristics. Human Reproduction 27 (4): 1080-1087. 
DiPietro, Janet. 2010. Psychological and psychophysiological considerations regarding the maternal-fetal relationship. Infant and Child Development 19: $27-38$.

Drabiak, Katherine, Carole Wegner, Valita Fredland, and Paul Helft. 2007. Ethics, law, and commercial surrogacy: A call for uniformity. Journal of Law, Medicine \& Ethics 35: 300-309.

Edelmann, Robert. 2004. Surrogacy: The psychological issues. Journal of Reproductive and Infant Psychology 22 (2): 123-136.

Elster, Jon. 1983. Sour grapes: Studies in the subversion of rationality. Cambridge, UK: Cambridge University Press.

Fischer, Susan, and Irene Gillman. 1991. Surrogate motherhood: attachment, attitudes and social support. Psychiatry 54 (1): 13-20.

Goecke, T., F. Voigt, F. Faschingbauer, G. Spangler, M. W. Beckmann and A. Beetz. 2012. The association of prenatal attachment and perinatal factors with pre- and postpartum depression in first-time mothers. Archives of Gynecology and Obstetrics 286 (2): 309-316.

Golombok, Susan, Jennifer Readings, Lucy Blake, Polly Casey, Alex Marks, and Vasanti Jadva. 2011. Families created through surrogacy: Mother-child relationships and children's psychological adjustment at age 7. Development Psychology 47: 1579-1588.

Growing Generations. Available at: http://www.growinggenerations.com. Accessed 16 July 2013. 
Gugucheva, Magdalina. 2010. Surrogacy in America. Cambridge, Mass.: Council for Responsible Genetics.

Gupta, Divya. 2011. Inside India's surrogacy industry. Guardian Weekly,

December 6. Available at:

http://www.guardian.co.uk/world/2011/dec/06/surrogate-mothers-india. Accessed 22 July 2013.

Hepper, Peter. 1996. Fetal memory: Does it exist? What does it do? Acta Padiatrica Supplement 416: 16-20.

Hofer, Myron. 2006. Psychobiological roots of early attachment. Current Directions in Psychological Science 15 (2): 84-88.

Hrubý, Radovan, Jozef Hašto, Peter Minárik. 2011. Attachment in Integrative Neuroscientific Perspective. Activitas Nervosa Superior Rediviva 53 (2): 4958.

Humbyrd, Casey. 2009. Fair trade international surrogacy. Developing World Bioethics 9: 111-118.

In re Baby M. 1988. Family Court Review 26: 69-77.

Jackson, Emily. 2001. Regulating reproduction: Law, technology and autonomy. Oxford, UK: Hart Publishing.

Jadva, Vasanti, Clare Murray, Emma Lycett, Fiona MacCallum, and Susan Golombok. 2003. Surrogacy: The experiences of surrogate mothers. Human Reproduction 18 (10): 2196-2204. 
Jadva, Vasanti, and Susan Imrie. 2014. Children of surrogate mothers: psychological well-being, family relationships and experiences of surrogacy. Human Reproduction 29(1): 90-96.

Kovacs, Gavor, Gary Morgan, Carl Wood, Catherine Forbes, and Donna Howlett. 2003. Community attitudes to assisted reproductive technology: A 20-year trend. Medical Journal of Australia 179: 536-538.

Kisilevsky, Barbara S., Sylvia M. J. Hains, Christine Ann Brown, Charlotte T. Lee, Bernadine Cowperthwaite, Sherri Schmidt Stutzman, Melissa L. Swansburg, Kang Lee, Xing Xie, Hefeng Huang, HaiHui Ye, Ke Zhang, and Zengping Wang. 2009. Fetal sensitivity to properties of maternal speech and language. Infant Behavior and Development 32 (1): 59-71.

Krishnan, Vijaya. 1994. Attitudes toward surrogate motherhood in Canada. Health Care for Women International 15 (4): 333-357.

Lasker, Judith and Dawn Murray. 2001. Attitudes toward technologies for conception: A 15-year follow up. Journal of Applied Social Psychology 31: $2165-2183$.

Laxton-Kane, Martha, and Pauline Slade. 2002. The role of maternal prenatal attachment in a woman's experience of pregnancy and implications for the process of care. Journal of Reproductive and Infant Psychology 20 (4): 253-266.

Lee, Ruby. 2009. New Trends in Global Outsourcing of Commercial Surrogacy: A Call for Regulation. Hastings Women's Law Journal, 20 (2): 275-300. 
Lindgren, Kelly. 2001. Relationships among maternal-fetal attachment, prenatal depression, and health practices in pregnancy. Research in Nursing and Health 24: 203-217.

Mampe, Birgit, Angela Friederici, Anne Christophe, and Kathleen Wermke. 2009. Newborns' cry melody is shaped by their native language. Current Biology 19: 1994-1997.

Medical Tourism Corporation. Available at: http://www.medicaltourismco.com/assisted-reproduction-fertility/low-costsurrogacy-india.php. Accessed 16 July 2013.

Mennella, Julie, Coren Jagnow, and Gary Beauchamp. 2001. Prenatal and postnatal flavor learning by human infants. Pediatrics 107 (6). Available at: http://www.pediatricsdigest.mobi/content/107/6/e88.short. Accessed 22 July 2013.

Moriceau, Stephanie, and Regina Sullivan. 2005. Neurobiology of infant attachment. Development Psychobiology 47 (3): 230-242.

Nafee, Tamer, William Farrell, William Carroll, Anthony Fryer and Khaled Ismail. 2008. Epigenetic control of fetal gene expression. BJOG: An International Journal of Obstetrics \& Gynaecology 115 (2): 158-168.

Parfit, Derek. 1984. Reasons and persons. Oxford, UK: Oxford University Press.

Parks, Jennifer. 2010. Care ethics and the global practice of commercial surrogacy. Bioethics 24: 333-340. 
Rimm, Jennifer. 2008-2009. Booming baby business: Regulating commercial surrogacy in India. University of Pennsylvania Journal of International Law 30: 1429-1462.

Satz, Debra. 2010. Why some things should not be for sale: The moral limits of markets. Oxford, UK: Oxford University Press.

Schneider, Carl. 1990. Surrogate motherhood from the perspective of family law. Harvard Journal of Law \& Public Policy 13 (1): 125-131.

Scott, Elizabeth. 2009. Surrogacy and the politics of commodification. Law and Contemporary Problems 72: 109-146.

Shetty, Priya. 2012. India's unregulated surrogacy industry. The Lancet 380: 1633-1634.

Shiffrin, Seana. 1999. Wrongful life, procreative responsibility and the significance of harm. Legal Theory 5 (2): 117-148.

Suzuki, Kohta, Rintaro Sawa, Kaori Muto, Satoshi Kusuda, Kouji Banno, and Zentaro Yamagata. 2011. Risk perception of pregnancy promotes disapproval of gestational surrogacy: Analysis of a nationally representative opinion survey in japan. International Journal of Fertility \& Sterility 5: 7885.

Tong, Rosemarie. 1990. The overdue death of a feminist chameleon: Taking a stand on surrogacy arrangements. Journal of Social Philosophy 21 (2): 4056.

van den Akker, Olga. 2007. Psychosocial aspects of surrogate motherhood. Human Reproduction Update 13: 53-62. 
Walsh, Judi. 2011. Definitions Matter: If Maternal-Fetal Relationships Are not Attachment, What Are They? Archives of Women's Mental Health 13: 449451.

Warnock, Mary. 1984. Report of the Committee of inquiry into Human Fertilisation and Embryology. Cmnd 9314. London, UK: HMSO.

Wertheimer, Alan. 1992. Two questions about surrogacy and exploitation. Philosophy \& Public Affairs 21: 211-239.

Wertheimer, Alan. 1996. Exploitation. Princeton: Princeton University Press.

Wilkinson, Stephen. 2003. The exploitation argument against commercial surrogacy. Bioethics 17: 169-187. 